\title{
Sustentabilidade no design de interiores: Modelo IDSRS adaptado - $O$ exemplo de uma residência em Itacimirim-BA
}

\author{
Sustainability in interior design: Adapted IDSRS model - The example of a residence \\ in Itacimirim-BA
}

\author{
SARMENTO, Ana Carolina de Lima; Ma.; Universidade Federal da Bahia \\ carol_sarmento@hotmail.com \\ SOUZA, Paulo Fernando de Almeida; Dr.; Universidade Federal da Bahia \\ paulosouza@ufba.br
}

\begin{abstract}
Resumo
Partindo da problemática "Como diminuir os impactos ambientais em projetos de interiores?", apresentamos neste artigo os resultados de uma pesquisa de Mestrado. O estudo tem como principal contribuição refletir sobre todas as etapas que envolvem o projeto de interiores, adequando esses ambientes aos parâmetros da sustentabilidade, a partir de uma metodologia de projeto que permita uma antecipação dos impactos ambientais em projetos de interiores. Partindo da análise do modelo IDSRS (Indicadores de Design, Sustentabilidade e Responsabilidade Social), desenvolvido por Souza (2007) para o contexto do design de produto, adaptado para uso no design de interiores. Afim de demostrar o modelo adaptado, tomamos como estudo de caso a construção de uma residência localizada em Itacimirim - BA, desde a concepção do projeto até a sua implementação/execução. Esta pesquisa configura-se de natureza exploratória e qualitativa, pois busca familiarizar-se com o tema, reunindo informações sobre as relações existentes entre sustentabilidade e design de interiores.
\end{abstract}

Palavras Chave: Design de Interiores; Indicadores de Sustentabilidade; Modelo IDSRS.

\begin{abstract}
Starting from the problematic "How to reduce the environmental impacts in interior projects?", We present in this article the results of a Master's research. The main contribution of this study is to reflect on all the steps involved in interior design, adapting these environments to the parameters of sustainability, based on a project methodology that allows an anticipation of environmental impacts in interior projects. Based on the analysis of the IDSRS (Design, Sustainability and Social Responsibility Indicators) model, developed by Souza (2007) developed in the context of product design, adapted for use in interior design. In order to demonstrate the adapted model, we took as a case study the construction of a residence located in Itacimirim - BA, from project design to implementation / execution. This research is of an exploratory and qualitative nature, as it seeks to familiarize itself with the theme, gathering information about the relationship between sustainability and interior design.
\end{abstract}

Keywords: Interior Design; Sustainability Indicators; Model IDSRS. 


\section{Introdução}

Atualmente, a maioria das referências que associam sustentabilidade ao design de interiores está relacionada à especificação de materiais, porém a sustentabilidade neste ramo do design, vai além do uso de um produto ecologicamente responsável. Está relacionada a projetos duráveis e norteadores, onde há maior interação entre profissionais responsáveis e clientes, resultando em projetos de qualidade (MOXON, 2012).

Estrada (2014, p. 11) enfatiza que "materiais eco amigáveis e métodos de produção socialmente corretos, desenvolvidos com responsabilidade social e ambiental, são, sem dúvida, os patamares por onde iniciar as interferências nas cadeias produtivas em qualquer segmento." Refletindo sobre a sustentabilidade no design de interiores, encontramos na literatura referências relacionadas apenas a produtos ecologicamente responsáveis, mas o que falar dos impactos ambientais gerados ao longo de todas as fases que envolvem um projeto de interiores? $A$ percepção ambiental, desde a criação à execução, não seria tão importante quanto o resultado final? Ou melhor, não seria o resultado final uma consequência desse processo? A partir disso, visando à pratica da sustentabilidade no design de interiores, neste estudo, objetiva-se contribuir com a antecipação dos impactos ambientais, a partir de uma metodologia que utiliza indicadores de sustentabilidade, design e responsabilidade social. Trata-se de uma reflexão que vai além do produto, enfatizando, sobretudo, todas as etapas do processo.

A palavra sustentável vem do latim sustentare, que significa sustentar, apoiar, conservar. $\mathrm{Na}$ teoria, esse conceito está relacionado a uma mentalidade, atitude ou estratégia ecologicamente responsável e socialmente justa. E na prática? Stephan (2014) defende que essa consciência ainda não encontra eco na prática cotidiana da sociedade. É a partir desse conflito entre teoria e prática que o objetivo desse estudo é definido, pois, como postula Jatobá (2014, p. 29), "essa não é uma discussão acadêmica ou teórica. Ela terá que acontecer na prática."

\section{Metodologia}

Este artigo é escrito na perspectiva de uma pesquisa exploratória, definida por Gil (2008, p. 27) como aquele método que "apresenta como principal finalidade, desenvolver, esclarecer e modificar conceitos e ideias, tendo em vista a formulação de problemas mais precisos ou hipóteses pesquisáveis em estudos posteriores". O estudo em si é resultado de uma investigação em nível de mestrado, que utilizou-se majoritariamente dos métodos de pesquisa qualitativa, estudo de caso e pesquisa fundamentada em dados, organizado a partir de uma análise descritiva e interpretativa.

Para demostrar o modelo adaptado, realizamos um estudo de caso, a partir de uma pesquisa de campo, com registros fotográficos e entrevistas com os envolvidos no processo. Optamos por investigar o caso desde as fases iniciais do projeto, a fim de demonstrar a antecipação dos impactos intencionados antes da concepção do projeto.

\section{Sustentabilidade no design de interiores}

Seguindo os ensinamentos de Papanek (1995), quando pensamos em ambientes concebidos de forma harmônica com as pessoas que neles conviverão, refletimos sustentabilidade e, por conseguinte, contribuímos para o desenvolvimento sustentável. Ao contrário do que geralmente vemos, projetos sustentáveis podem e devem influenciar o desenvolvimento sustentável quando inseridos como uma prática de um projeto de qualidade, e não como uma 
opção de escolha (EDWARDS, 2013; MOXON, 2012).

Segundo Moxon (2012), o projeto sustentável não deve ser algo opcional, mas sim, o essencial de um projeto de qualidade. Corroborando com esse pensamento, Fry (2009), afirma que:

Dar vida, digamos, a produtos, processos ou espaços ambientalmente limpos não é chegar a uma solução, pois a mudança material não ocorrerá, a menos que o limpo seja desejado e desloque o que ora ocupa o lugar (FRY, 2009, p. 59).

A partir desses pensamentos, precisamos refletir quais as necessidades que nos prendem a produtos e espaços, ou estilos de vida que causam impactos ambientais. A necessidade de fato precisa existir, afinal, é a partir dela que buscamos as soluções para um projeto, entretanto, para Fry (2009), a necessidade precisa ser mais bem entendida.

Em 1970, Papanek (apud FRY, p. 60) já afirmava "o design há de ser uma ferramenta inovadora, altamente criativa e interdisciplinar em resposta às legítimas necessidades dos homens". Para Fry (2009, p. 59), "necessidade é aquilo que temos; faz parte do nosso estar-nomundo [...] é uma exigência cultural dada, junto da qual nascemos e crescemos". O autor ainda complementa,

Em geral o que achamos necessário a maioria de nós é, na verdade, a negação de nossos meios de sobrevivência. Separar as necessidades que amparam a vida das que a destroem não deve ser visto como preocupação moral e sim como imperativo ecológico (FRY, 2009, p. 61).

Papanek (1975), Fry (2009) e Moxon (2012) corroboram do mesmo pensamento ao relatar, em seus discursos, que a necessidade não pode ser vista de forma fixa e universal, pois o que é necessário para um povo pode não ser para outro. É preciso perceber as necessidades específicas de cada um, pois "o design modela boa parte do mundo que moldamos e nos molda (FRY, 2009, p. 59)". No Design, é preciso se ter muito cuidado ao que de fato é uma necessidade, para que não sejamos conduzidos por um movimento ontológico, onde a necessidade tende a ganhar foros de "necessidade da vida em si" e deixa de ser "necessidade humana". Fry (2009) afirma a dificuldade em tornar visível a necessidade, e pondera que é preciso haver uma desconstrução: reconstruir para reedificar (FRY, 2012).

A sustentabilidade no design de interiores vai além de um produto ecologicamente responsável. É preciso refletir o que, de fato, é uma necessidade pessoal e o quanto nos deixamos levar por uma necessidade imposta pelos padrões de consumo. Fry (2009) chama atenção para essa "necessidade" criada para suprir as transições do mercado, onde se impõe a condição do Ser e, por conseguinte, perde-se a soberania do eu. Tal transição ocorre concomitantemente quando colocamos o sujeito/usuário na condição de consumidor.

Algumas decisões básicas no projeto de interiores podem conduzir um comportamento sustentável futuramente, por isso, saber de que forma se dará o seu funcionamento é uma estratégia sustentável no momento de sua concepção, e deve ser reconsiderada ao longo de todo processo. O autor nos apresenta alguns exemplos que induzem a uma prática sustentável, tais como: o planejamento de espaços que fazem melhor uso da iluminação natural, evitando que seus ocupantes ascendam luzes artificias; e até mesmo a distribuição de coletores perto de fontes de resíduos, estimulando a separação do lixo e a reciclagem (MOXON, 2012).

No entanto, no design de interiores, percebe-se que a necessidade e os desejos individuais 
de cada usuário interferem diretamente no desenvolvimento do projeto, que é único, e não plural, como no design de produto. Para que um projeto de interiores supra as expectativas daqueles que farão uso dele, é imprescindível que a "necessidade" de seus usuários preencha uma perspectiva essencial e objetiva para cada ser, em uma relação de pertencimento do ser-do-mundo e não do ser-no-mundo. Por fim, deve-se acabar com um modismo insustentável que atribui ao design de interiores uma superficialidade que não condiz com a sua essência.

\subsection{Indicadores de sustentabilidade: Modelo IDSRS adaptado}

Indicadores de sustentabilidade são informações qualitativas e quantitativas que contribuem para tomada de decisões em um determinado sistema natural, com o objetivo de minimizar os impactos ambientais. Souza (2007) aponta que os indicadores são sinais mensuráveis, que podem atribuir ideias a abstrações de algum sistema e, a partir disso, contribuir com seu estado de funcionamento, indicando pontos de maior relevância, os quais devem ser avaliados. Entretanto tais informações precisam ser compreendidas, para que sejam interpretadas; logo, um indicador só será útil se a qualidade dessa informação estiver diretamente associada à precisão com que os dados são apresentados, desde a coleta até sua leitura e entendimento (SOUZA, 2007).

O modelo de Indicadores de Design, Sustentabilidade e Responsabilidade Social - IDSRS avalia as quatro fases do processo de desenvolvimento de um produto: a) Produção; b) Manufatura; c) Reciclagem; d) Reuso/ Redesign, conforme figura 1. Cada fase apresenta um conjunto de indicadores que auxiliam no processo de tomada de decisões e avaliam desde o consumo a sua capacidade de decomposição biodegradação e reutilização e são decisivas no que diz respeito às expectativas da sociedade (SOUZA, 2007).

Figura 1 - Indicadores associados às demandas sociais e ambientais dos processos design.

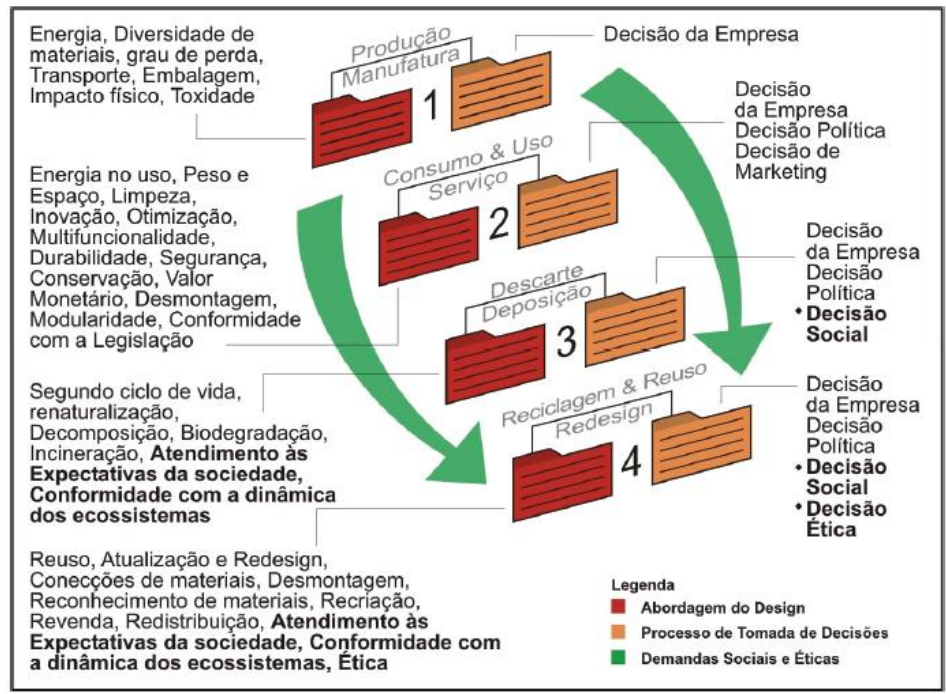

Fonte - SOUZA, 2007

A partir disso, adaptamos o modelo para uso no design de interiores, com o objetivo de antecipar os impactos ambientais, através de parâmetros de sustentabilidade que contribuam na transformação da prática do Design de Ambientes (SARMENTO e SOUZA, 2016; SARMENTO, 2017). 
Em princípio, redefinimos algumas fases e inserimos a fase de Pré-projeto, como fase I, por julgar que alguns detalhes são importantes e norteadores para concepção de um projeto sustentável, conforme descrito no quadro 1.

Quadro 1 - Modelo IDSRS adaptado para uso no Design de Interiores.

\begin{tabular}{|c|c|}
\hline Fases & Indicadores \\
\hline I. Pré-projeto & $\begin{array}{l}\text { - Adequação e conformidade do terreno } \\
\text { - Transportes públicos e serviços acessíveis } \\
\text { - Conforto ambiental }\end{array}$ \\
\hline II. Projeto & $\begin{array}{l}\text { - Conforto ambiental } \\
\text { - Preservação da vegetação existente } \\
\text { - Flexibilidade da construção } \\
\text { - Acessibilidade/mobilidade } \\
\text { - Especificação dos materiais/mobiliário } \\
\text { - Economia de água e energia } \\
\text { - Conformidade com a legislação }\end{array}$ \\
\hline III. Implementação/ Execução & $\begin{array}{l}\text { - Gestão do projeto } \\
\text { - Comunicação entre os envolvidos } \\
\text { - Adequação dos materiais/mobiliários } \\
\text { - Grau de toxidade } \\
\text { - Economia de água e energia } \\
\text { - Conformidade com a legislação }\end{array}$ \\
\hline IV. Descarte/ Reciclagem/ Reuso & $\begin{array}{l}\text { - Gestão de resíduos } \\
\text { - Deposição/Descarte, } \\
\text { - Facilidade na desconstrução } \\
\text { - Conformidade com a legislação } \\
\text { - Reciclagem/Reutilização }\end{array}$ \\
\hline V. Uso/ Serviço & $\begin{array}{l}\text { - Facilidade para manutenção } \\
\text { - Automação } \\
\text { - Bem-estar } \\
\text { - Economia de água e energia } \\
\text { - Multifuncionalidade } \\
\text { - Conformidade com a legislação }\end{array}$ \\
\hline
\end{tabular}

Fonte: SARMENTO, 2017

Observamos que a fase I de Pré-projeto avalia o terreno/espaço antes mesmo da concepção do projeto, isto é, a acessibilidade a serviços e transportes públicos, o desconforto do entorno, assim como a preservação da vegetação existente. A partir do exemplo do modelo IDSRS aplicado ao desenvolvimento de produto, julgamos que, no Design de Interiores, precisaríamos avaliar alguns detalhes que antecedem a fase de projeto, por isso, definimos a fase de Pré-projeto.

$\mathrm{Na}$ fase II avaliamos, a orientação solar, a acessibilidade, o conforto ambiental, a economia de água e energia, a flexibilidade da construção para futuras intervenções, a acessibilidade e a mobilidade atuais e futuras dos clientes, assim como a conformidade com a legislação e preservação de vegetações e construções existentes. É a fase norteadora do projeto e, portanto, de grande relevância. Nesta fase, destacamos a importância do designer de interiores para a definição do layout do projeto, tomando como partida o projeto arquitetônico. Com isso, são definidos os demais projetos que precisam ser concluídos para início da obra: hidráulico, luminotécnico, elétrico. 
A fase III, corresponde à Implementação/Execução, em que o cliente vai perceber volumetricamente a construção do projeto. Observa-se, nesta fase, a tendência de se gerar mais impactos ambientais, uma vez que corresponde à fase de execução do que foi projetado. Por isso, ressaltamos a importância da fase anterior para nortear as demais. A fase IV, Descarte/Reciclagem/Reuso, está relacionada aos resíduos da construção, ao descarte e reutilização do entulho, assim como, a facilidade de reconhecimento dos materiais utilizados.

Por fim, a fase $V$ é o momento de compreender e viver o espaço. É o fim de um ciclo que se inicia antes mesmo da concepção do projeto. É a fase de Uso/Serviço diz respeito ao ambiente já construído. Esta fase, só será possível uma avaliar após a ocupação do ambiente, uma vez que, observaremos se os ocupantes do espaço foram sensibilizados quanto ao uso do ambiente. De que forma esses ambientes estão sendo utilizados? Os seus ocupantes foram sensibilizados quanto às questões ambientais que estiverem presente nas outras etapas? $\mathrm{Na}$ fase de Uso/Serviço, avaliaremos desde a facilidade para manutenção, economia de água e energia a multifuncionalidade dos espaços e o bem-estar que o ambiente oferece pós-ocupação.

Observamos que todas as etapas da construção são interdependentes, e uma complementa a eficácia da outra, pois não existe execução se não houver projeto, e não existe um projeto que não leve em consideração detalhes norteadores e decisivos para a concepção do mesmo. Destacamos que a fase II, por se tratar, de fato, da concepção do projeto, torna-se a mais relevante de todas e, por isso, norteadora para as demais. É nessa fase que ressaltamos a importância da atuação do designer de interiores para definição do layout dos ambientes. Ressaltamos também que, nesse modelo adaptado, nem sempre todos os indicadores serão aplicados a todos os projetos, e nem todas as fases serão consideradas, visto que alguns se encontrarão em estágios mais avançados de construção.

O uso de indicadores de sustentabilidade deve ser compreendido como uma ferramenta estratégica que propõe novas maneiras de projetar. Ainda que seja desafiador, precisamos evoluir na relação entre sociedade e meio ambiente, para que tenhamos harmonia entre ambos. É preciso repensar maneiras de vivenciar o cotidiano, interagindo com a natureza e gerando menos impactos ao meio ambiente. A multidisciplinaridade, na busca de soluções entre os envolvidos na perspectiva da construção civil, por exemplo, é de suma importância quando pensamos na sustentabilidade.

\section{0 exemplo de uma residência em Itacimirim - BA}

Para demostrarmos o modelo de Indicadores de Design, Sustentabilidade e Responsabilidade Social - IDSRS adaptado, escolhemos uma residência situada em Itacimirim - BA. A demonstração do uso dos indicadores foi desde a fase de pré-projeto à implementação/execução da casa. O requisito principal para escolha da casa foi ter o projeto de interiores completamente definido antes mesmo da sua construção, pois, precisaríamos de um projeto, cujo layout definitivo fosse norteador para sua execução, uma vez que, a partir disso, foram definidas as instalações elétricas e hidráulicas e as possíveis alterações, de acordo com as necessidades de seus moradores. Com isso, acreditamos que há um menor índice de retrabalhos, e consequentemente diminui-se o desperdício e os resíduos da construção. No âmbito deste artigo, escolhemos apresentar a demonstração de apenas uma fase, pois não teríamos espaço suficiente para expor todo modelo. Diante disso, escolhemos a fase de implementação/execução, fase III, por se tratar da construção e, notadamente, a fase de maior impacto ambiental. 
A casa está situada em um condomínio na Rodovia BA-099, na região de Itacimirim, pertencente ao município de Camaçari, localizado a $74 \mathrm{~km}$ da cidade de Salvador. Os proprietários, um casal de meia idade, moram sozinhos e recebem a visita dos filhos eventualmente. Apesar disso, ambos têm famílias grandes. A casa é composta por pavimento inferior e superior, cujo térreo inclui, área de lazer, piscina, área gourmet, estar, jantar, lavabo, suíte 1, suíte 2, cozinha, área de serviço, dependência e depósito, conforme figura 2.

Figura 2: Térreo (sem escala)

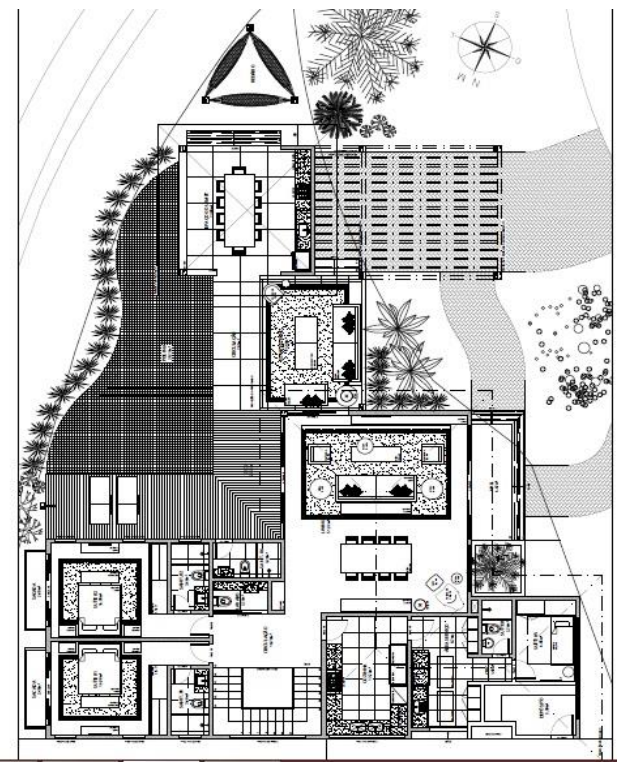

Fonte: Plantas cedidas pelo escritório MB Arquitetura, 2017

No pavimento superior concentra-se a área íntima com duas suítes, sendo uma delas a suíte máster, composta por área de dormir, closet e banheiro. Dentro das exigências dos proprietários, foi solicitada uma suíte máster ampla, com vista para área de lazer e espaço de vestir separado do espaço de dormir, conforme figura 3.

Figura 3: 1으 Pavimento (sem escala)

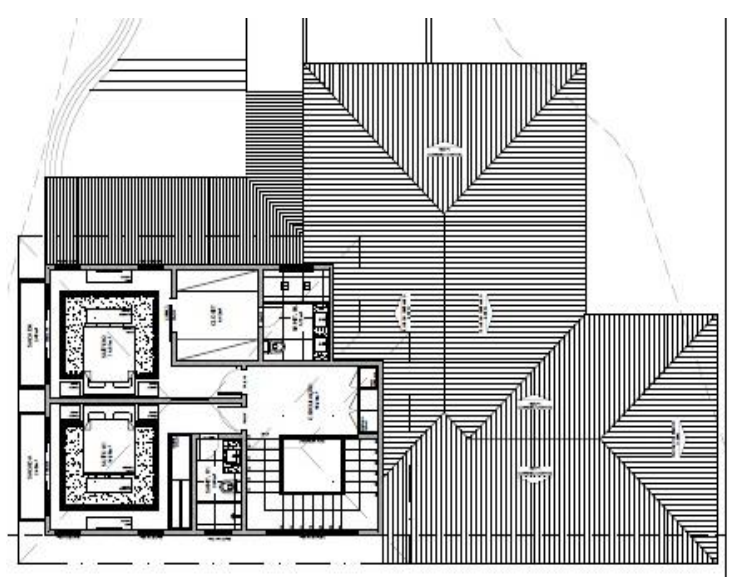

Fonte: Plantas cedidas pelo escritório MB Arquitetura, 2017 
Nesta residência, os proprietários precisavam ter uma área social espaçosa, para acomodar família e receber os amigos. Dentro do plano de necessidades do casal, havia o pedido de suítes no primeiro pavimento para acomodar aqueles que tivessem dificuldade para usar a escada como, idosos, cadeirantes, e até mesmo, para uma necessidade futura.

Observa-se que, proporcionalmente, as áreas sociais são maiores que as demais. Trata-se de uma estratégia que estimula a coletividade, uma vez que favorece o convívio familiar, consequentemente, diminui a individualidade, pois as pessoas passam a utilizar as áreas sociais para conviver, e as íntimas para dormir. O projeto de interiores pode estimular novos modos de vida, portanto, é de suma importância que essa percepção venha do profissional durante a concepção do projeto.

Como parte da metodologia utilizada ao longo da pesquisa, realizamos entrevistas com os profissionais e proprietários a fim de compreender todas as etapas do processo, desde os motivos para escolha do terreno à construção da casa. A partir disso, apresentamos a demonstração do Modelo IDSRS adaptado, a partir de um memorial descritivo-analítico das fases que compõe o objeto de estudo. Ressaltamos que, neste projeto, os indicadores não foram norteadores para as tomadas de decisões durante as etapas de produção, ou seja, não serviu como uma metodologia, pois, nesta fase, o objetivo inicial do estudo foi adaptar o modelo existente para uso no design de interiores. A formulação das entrevistas baseou-se nos indicadores adaptados.

Acompanhamos a construção da casa com visitas em loco, registros fotográficos de todas as etapas da obra e entrevistas com os principais envolvidos. Chamaremos os entrevistados de $A$, $B, C$ e D, conforme descritos no quadro a seguir. O objetivo da entrevista foi compreender como se deu toda a etapa de produção, desde a escolha do terreno a construção da casa. Para cada fase, gerou-se um conjunto de perguntas relacionadas aos indicadores e por isso foram direcionadas apenas àqueles que atuaram naquela fase. O quadro a seguir apresenta o perfil dos entrevistados, sua atuação e função durante o processo, e em quais fases atuaram como agentes decisores.

Quadro 2 - Perfil dos entrevistados

\begin{tabular}{|c|c|c|c|c|c|c|c|}
\hline Entrevistado & Perfil & Função/Relevância para & \multicolumn{5}{|c|}{ Fases envolvidas } \\
\hline$A$ & $\begin{array}{l}\text { Arquiteto, } 28 \text { anos, formado desde } \\
\text { 2012, sócio do escritório MB Arquitetos. }\end{array}$ & $\begin{array}{l}\text { Criar, desenvolver e } \\
\text { acompanhar os projetos. }\end{array}$ & & II & III & & \\
\hline B & $\begin{array}{l}\text { Arquiteta, } 30 \text { anos, formada desde } \\
\text { 2012, sócia do escritório MB Arquitetos. }\end{array}$ & $\begin{array}{l}\text { Criar, desenvolver e } \\
\text { acompanhar os projetos. }\end{array}$ & & II & III & & \\
\hline C & $\begin{array}{l}\text { Mestre de obra, } 35 \text { anos, atua na área } \\
\text { há } 17 \text { anos. }\end{array}$ & $\begin{array}{l}\text { Executar e gerenciar a } \\
\text { obra. }\end{array}$ & & & III & IV & \\
\hline D & $\begin{array}{l}\text { Proprietário, } 54 \text { anos, casado, não tem } \\
\text { filhos, músico, compositor e sócio de } \\
\text { uma empresa do ramo de materiais } \\
\text { hospitalares. }\end{array}$ & Contratante & I & II & & & $\mathrm{V}$ \\
\hline
\end{tabular}

Fonte: SARMENTO, 2017

Neste projeto, os arquitetos, entrevistados A e B, não foram contratados para gerenciar e 
executar a obra, mas realizaram algumas visitas técnicas esporádicas, para supervisionar a execução. Atuaram na fase de projeto e implementação/execução, por meio das visitas técnicas. 0 entrevistado $C$ já trabalha para a família há algum tempo, é mestre de obra e ficou responsável por executar e gerenciar a construção, por isso, atuou nas fases implementação/execução e reciclagem/descarte/reuso, respectivamente, III e IV. Por fim, o entrevistado D, proprietário do empreendimento, atuou nas fases I, II e IV. A fase V diz respeito ao uso/serviço, portanto só pode ser avaliado no momento pós-ocupação, e o único agente decisor é o proprietário que usará o ambiente.

Destacamos alguns trechos das entrevistas e ilustramos com registro fotográfico, para compreender a evolução e a execução da obra. A partir disso, interpretamos individualmente a importância de cada indicador para tomada de decisão de cada fase, sobretudo cada agente envolvido. Ressaltamos que iniciamos a análise pela fase de pré-projeto, pois julgamos que alguns aspectos são norteadores para fase de projeto e precisam ser pontuados antes mesmo de sua concepção, revelando aspectos importantes para os indicadores desta etapa.

Os indicadores dessa etapa nos ajudam a compreender quais impactos podem ser evitados ao longo de seu desenvolvimento, conforme quadro 3.

Quadro 3-Indicadores adotados na Fase III

\begin{tabular}{c|l}
\hline Fase & \multicolumn{1}{c}{ Indicadores } \\
\hline & • Gestão do projeto \\
& - Comunicação entre os envolvidos \\
III. Implementação/ Execução & - Gdequação dos materiais/mobiliários \\
& - Economia de toxidade \\
& • Conformidade com a legislação \\
\hline
\end{tabular}

Fonte: SARMENTO, 2017

Para esta fase, entrevistamos os arquitetos e o mestre-de-obras (entrevistados A, B e C, respectivamente). Inicialmente, questionamos como foi à comunicação entre eles ao longo da construção.

A gente sempre teve, graças a Deus, uma comunicação muito direta com a obra, seja por ligação, por WhatsApp, o que quer que seja, sempre teve uma troca de informação muito positiva, tanto da parte deles com a gente, e da gente com eles. A parte de planta era basicamente direcionada para C e ele entregava isso na obra (...) (Entrevistado A, 2017).

Um dos índices de maior retrabalho em obras/reformas é a falta de comunicação entre os envolvidos. Sabemos que o projeto demasiadamente especificado é um instrumento de comunicação entre eles. É normal que, ao longo da obra, ocorram algumas alterações, por isso, perguntamos se as plantas estavam sempre atualizadas.

Todas atualizações ou discussões eram feitas de imediato para que não atrasasse a obra e direcionadas para lá para que fosse executada da maneira correta (Entrevistado A, 2017).

Esteve. Tinha vez que $D$ trazia e passava pro A, e a gente ligava pra ele e eles ligavam pra gente (Entrevistado B, 2017). 
Em uma das visitas à obra, observamos que os pontos elétricos das suítes estavam locados errados, pois os projetos haviam sido mudados, e as plantas técnicas não foram atualizadas na obra. Então questionamos ao mestre-de-obras o porquê do ocorrido:

Assim, eles fizeram um projeto, acho que a cama ficava aqui, e essa esteira aqui. Aí, na nova programação, ele fez as mudanças, mas não criou o projeto mais. (Entrevistado C, 2017).

A falta de comunicação na obra ainda é muito recorrente e altamente impactante, uma vez que gera desperdício e retrabalhos. Este indicador chama atenção para a importância das plantas estarem sempre atualizadas no decorrer da construção, sobretudo, da necessidade de visitas técnicas por parte dos profissionais responsáveis pelo desenvolvimento do projeto. Boa parte dos entulhos poderia ser evitado se houvesse maior interação entre os envolvidos.

Ao longo das visitas, observamos que uma das paredes da área gourmet foi demolida para ser reconstruída, conforme a figura 4.

Figura 4: Mosaico fotográfico da área gourmet - residência Itacimirim - BA

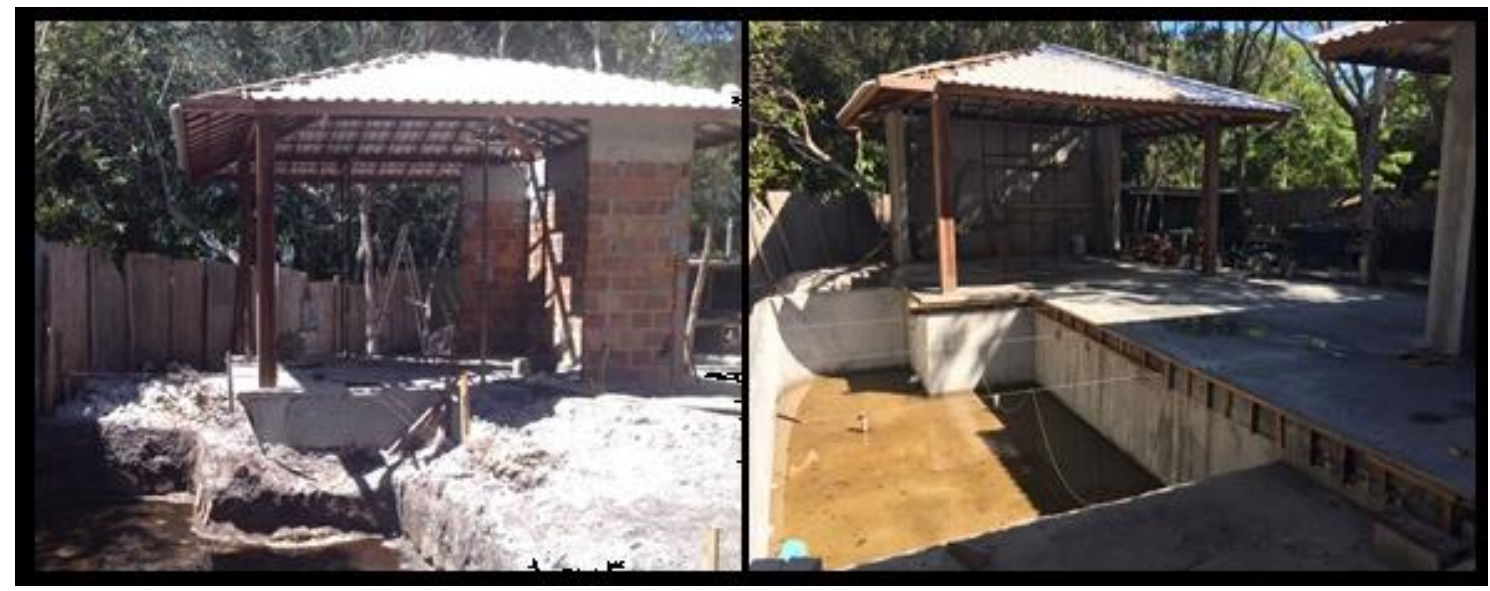

Fonte: SARMENTO, 2017

Ao questionar os profissionais envolvidos, os mesmos justificaram que foi uma escolha do proprietário, para que houvesse maior integração com a sala de estar.

Não, a gente não implantou o gourmet daquele jeito, a gente implantou ele virado também para a floresta. Virado para a parte da frente, até porque era o melhor aproveitamento da ventilação da casa. Ficava voltada totalmente pro nascente, enfim, ela era voltada para a melhor posição da casa, e no decorrer da obra ele achou que a gente tinha criado um paredão na frente da casa, aquilo incomodou (Entrevistado A, 2017).

Eu acho que ele vai se arrepender (Entrevistado B, 2017).

Talvez, se ele tivesse deixado à obra seguir mais um pouquinho, aquilo teria tomado corpo, e ele teria internalizado melhor (Entrevistado A, 2017).

Até porque tem a questão, quando tirar o tapume, aquilo ali vai se tornar fachada, então ele não vai ter privacidade nenhuma naquela área. Agora, eu acredito que quando fizer um projeto paisagístico, vai acabar acontecendo dele ter privacidade, e continuar com essa, ele queria mais abertura entre as 2 extremidades, ele queria (Entrevistado B, 2017). 
É natural surgirem algumas mudanças ao longo da construção/reforma, seja por erros de projeto, ou por decisão dos próprios clientes. Neste caso, o proprietário achou que, inicialmente, a parede construída estaria bloqueando a integração entre sala de estar e área gourmet. Entretanto, ao desenvolverem o projeto, os arquitetos construíram a parede voltada para o nascente, levando em consideração o conforto ambiental e a privacidade da área de lazer. Um projeto de arquitetura/interiores está diretamente relacionado com os sonhos, desejos, sobretudo, com a saúde e bem-estar daqueles que conviverão.

O design de interiores e a arquitetura, geralmente, são associados a padrões estéticos e superficiais, e, em sua maioria, a funcionalidade dos espaços é colocada em segundo plano. Cabe a nós, profissionais, inverter essa ordem e convencer que um projeto tem de ser defendido pela sua essência. Não sabemos dizer, ao certo, se foi isso que ocorreu, mas é perceptível no discurso dos profissionais, e na decisão do cliente, que essa parte do projeto não foi defendida.

O projeto ainda sofreu mais uma alteração significativa, dessa vez, no janelão da escada, conforme figura 5. Observamos que as janelas centrais se abrem, porém, inicialmente, não havia sido planejada assim.

Figura 5: Janelão da escada

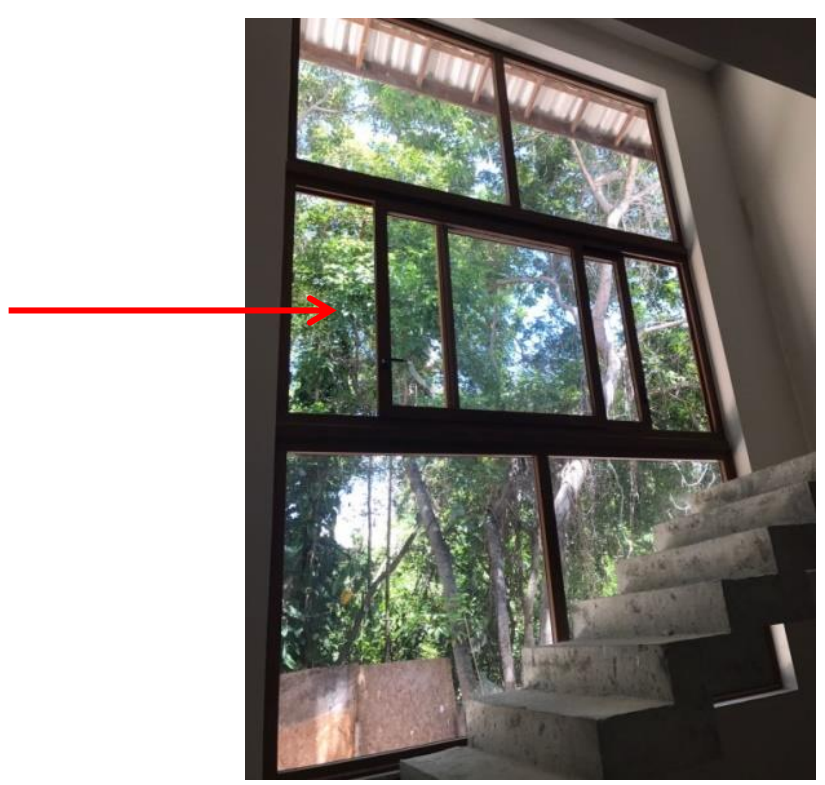

Fonte: SARMENTO, 2017

De fato, a abertura favorece a entrada de ventilação natural, mas, inicialmente, os arquitetos a planejaram apenas para se ter uma vista panorâmica da área externa. No relato do cliente, percebe-se uma preocupação com a ventilação e uma repulsa ao prejuízo financeiro.

Quando você analisar minha preocupação com a ventilação, eu tive um prejuízo de 3 mil e 500 reais, porque aquela panorâmica da escada, era todo fechado, era todo, tinha aberto uma parte, para abrir e fechar, para ventilar. Aí, a questão visual, e não ser confortável. la ser lindo ali tudo fechado, mas sem abertura eu não queria. Por erro de comunicação, entre as partes, o cara fez fechada. (...) Porque em todo tempo na minha cabeça era pra ser aberto, eu jamais iria imaginar que uma pessoa ia fazer aquilo ali ser uma abertura, porque o propósito daquilo também é ventilar (Entrevistado D, 2017). 
É perceptível que os profissionais levaram em consideração os padrões estéticos em vez da funcionalidade, e, mais uma vez, a apresentação e a aprovação do projeto não foram compreendidas. Neste caso ressaltamos a importância de colocar as práticas sustentáveis acima de qualquer padrão puramente estético.

Quanto à adequação dos materiais e mobiliários, perguntamos aos arquitetos e ao mestre de obra se o fato de a marcenaria ter sido definida e comprada no início da construção favoreceu o desenvolvimento da obra.

Facilita muito. Quando a gente trata com empresa geralmente de modulado, os módulos são muito específicos e às vezes se você não faz esse fechamento antes, para que a empresa possa compatibilizar essa questão de pontos, você acaba fazendo e refazendo para que o armário caiba no local certo, então, para a gente, essa questão de armário é sempre fundamental para que o cliente feche antes para poder minimizar o problema futuro da obra (Entrevistado A, 2017).

É mais prático, diminui bastante a quantidade retrabalhos, porque às vezes é... eu arrumo um móvel pronto, chegou pra instalar, a gente está esperando, ai para por aqui, termina essa parte aqui, fecha, deixa ai parado esperando vocês instalar. $O$ rodapé teve lugar que a gente já deixou só na posição, e depois a gente continuou depois que instalou (Entrevistado C, 2017).

Muito. Muito. Eu estava pensando nisso outro dia, falei, “... Se eu fosse pela, talvez se eu fosse fazer uma coisa, eu acho que iria..." aí sim, aí eu ia ficar maluco. Porque o tralho iria ser muito maior...muito (Entrevistado D, 2017).

Observamos que os três entrevistados concordam com a definição e compra do projeto de interiores, mais especificamente, a marcenaria planejada no inicio da construção. Compreende-se que essa definição corresponde a uma parte significativa de um projeto de interiores. É uma prática que favorece o desenvolvimento da obra, uma vez que todos os pontos hidráulicos, elétricos e luminotécnicos são executados em seus locais adequados, e não de forma genérica, como geralmente acontece. Observa-se no discurso do arquiteto, que o mesmo pontua a importância da compatibilização das plantas, e, todos concordam que diminui o índice de retrabalhos, consequentemente, menos entulho, menos lixo.

Quanto à adequação dos materiais, questionamos aos arquitetos e mestre-de-obras se houve a preocupação em deixar um estoque para futuras necessidades. Ambos nos responderam que há estoque de acabamentos.

A gente, sempre quando faz a compra do material, a gente indica, principalmente numa casa, a gente indica que se guarde... (Entrevistado $A, 2017$ )

10\% (Entrevistado B, 2017).

$10 \%$ pelo menos, pra você, se eventualmente precisar refazer um serviço, você tem a reposição do mesmo lote, que é um grande problema hoje que a gente enfrenta. Aí a gente sempre indica, que faça isso, se o cliente tiver depósito, como é o caso da casa (...) (Entrevistado A, 2017).

No que diz respeito à facilidade para remoção, o entrevistado respondeu que:

Assim, onde não tem epóxi, você quebra mas... aí você bate aqui, e é mais fácil você soltar, porque não tem tanta aderência no epóxi. No epóxi, você tem que cortar o 
material aqui. É porque geralmente o epóxi tem assim, no rejunte comum, ele pega sujeira, penetra sujeira (...) Ele só é ruim de tirar, mas em termos de qualidade, durabilidade, em termos de não passar umidade, jamais vai penetrar, como muitos penetram, umidade aqui, ele não penetra (Entrevistado C, 2017).

$\mathrm{Na}$ fase de projeto, um dos indicadores de sustentabilidade está relacionado à escolha e especificação de materiais e mobiliário. Nesta fase de execução, é preciso refletir sobre a adequação desses produtos ao projeto, sobretudo, o tipo de fixação que facilite a desmontagem e reciclagem. $O$ estoque de materiais também se consolida como uma prática sustentável, uma vez que, em uma necessidade futura, é possível fazer um reparo, sem necessariamente trocar todo revestimento.

Com relação ao grau de toxidade dos materiais, questionamos ao mestre se algum material já havia causado alguma reação alérgica nos profissionais envolvidos, e como se dá o uso de equipamentos de segurança, já que observamos que alguns usam e outros não.

Não. Nunca causou nenhuma reação alérgica. Com relação aos equipamentos de segurança, às vezes querem usar chinelo, mas no início da obra todo mundo usou sapato, a bota, depois... é que no final já vai relaxando mais. (Entrevistado C, 2017).

Em qualquer obra/reforma, seja ela de grande ou pequeno porte, é preciso garantir a segurança de seus trabalhadores, pois as normas exigem que sejam utilizados os Equipamentos de Proteção Individual (EPI), como, botas, máscaras, óculos, capacete e protetores auriculares, a fim de evitar acidentes de trabalho. O uso de EPI é fundamental para garantir a saúde e a segurança do trabalhador, além de prevenir que os profissionais fiquem expostos a doenças ocupacionais, que podem comprometer sua capacidade produtiva antes e depois da fase ativa do trabalho. Portanto o uso de EPI diminui o grau de toxidade entre os envolvidos e cumpre as normas da legislação.

Quanto à economia de água e energia no período da construção, observamos que não houve iniciativas nesse sentido.

A gente usou energia, água normal, desde o início. E energia também, normal (Entrevistado C, 2017).

Não, mas basicamente, tinha um problema do próprio terreno, que é muito fechado, então escurecia muito a casa, mas eu acho que não precisou muito de energia para luz, a maior parte da energia foi destinada para maquinário, mas para luz foi pouco (...) (Entrevistado A, 2017).

A fase de execução, geralmente, é a mais impactante, por ser a etapa de construção. É preciso buscar iniciativas que visem, também, à economia de água e energia nesse processo e não apenas no objeto final. Os impactos gerados no processo de obra/reforma são altamente prejudiciais ao meio ambiente e precisam ser diminuídos. Neste estudo, observa-se que nenhuma iniciativa foi tomada a esse respeito, entretanto o horário de trabalho dos profissionais envolvidos na execução iniciava às 7:30 e encerrava-se às 16:30, e, por isso, favoreceu a economia de energia, uma vez que não foi necessário o uso de iluminação artificial, logo, a energia foi destinada apenas ao uso de equipamento e maquinários.

Com relação à conformidade com a legislação, nesta etapa, a obra seguiu as normas internas do condomínio, uma vez que as mesmas são consolidadas de acordo com as normas municipais. No que diz respeito às normas de construção, tudo foi executado de acordo com projeto aprovado na prefeitura. Ao longo do processo, a obra recebeu a visita de uma fiscal da 
prefeitura, que fiscalizou se a execução ocorria de acordo com o projeto aprovado pela entidade fiscalizadora. No mais, ressaltamos desconformidade na segurança dos trabalhadores, e no descarte de resíduos sólidos.

\section{Conclusão}

Diante da escassa literatura especializada em sustentabilidade no design de interiores, sobretudo em língua portuguesa, que esteja além de um produto ecologicamente responsável, essa dissertação traz para o design de interiores um roteiro metodológico que relaciona a prática do design de interiores a aspectos socioambientais. O principal contributo deste estudo é refletir sobre as etapas do design de interiores, desde a concepção do projeto a fase de pós-ocupação, uma vez que, a sustentabilidade deve ser aplicada como um requisito obrigatório para qualquer projeto de design.

O objetivo deste estudo foi demonstrar o uso dos indicadores do Modelo de Indicadores de Design, Sustentabilidade e Responsabilidade Social - IDSRS adaptado para uso em design de interiores. As entrevistas foram elaboradas com base nos indicadores eleitos e realizadas com os principais envolvidos no projeto: cliente, arquitetos e mestre-de-obras. As respostas deste estudo nos fazem refletir o quanto o processo de construção/reforma ainda é impactante para o meio ambiente. O modelo IDSRS adaptado proporciona aos profissionais da área uma metodologia de projeto que auxilia na tomada de decisões baseadas em conceitos e práticas socioambientais. Com isso, diminui-se a probabilidade de erros e retrabalhos, logo, percebe-se uma diminuição dos impactos ambientais desde as fases iniciais de projeto. Além disso, indicadores como: conforto ambiental, demanda de água e energia, especificação de materiais, acessibilidade, multifuncionalidade, etc., propostos no modelo como elementos essenciais para avaliação no processo de design, são pontos que devem fazer parte de todo e qualquer projeto ecologicamente responsável.

Para tanto, quando o designer se insere no mercado como agente proativo, pode, por meio dos seus projetos, colabora com a disseminação de um comportamento social e ambientalmente responsável, afinal, a sustentabilidade é um termo que deveria estar presente no discurso direto entre profissionais e clientes. Nessa perspectiva, ao conhecer a importância de ações mais sustentáveis, o designer contribui para uma prática projetual educativa em cada etapa de tomada de decisões, onde, a funcionalidade do uso e a percepção ambiental estão acima de quaisquer modismos ou superficialidades impostas pelo mercado.

\section{Referências}

EDWARDS, B. O guia básico para a sustentabilidade. 1ำ ed. São Paulo: G. Gill, 2013.

ESTRADA, M. H. O pensar sustentável. In: JATOBÁ, Waldick (org). In: Desafios do design sustentável brasileiro $=$ Challenges of Brazilian sustainable design. São Paulo: Versal, 2014.

FRY, T. Introdução. In: FRY, T. Reconstruções: estética, design, filosofia. São Paulo: Editora da Universidade de São Paulo, 2009.

GIL, A. C. Métodos e técnicas de pesquisa social. 6. ed. São Paulo: Atlas, 2008.

JATOBÁ, W. O design sustentável. In: JATOBÁ, Waldick (org). Desafios do design sustentável brasileiro. Challenges of Brazilian sustainable design. São Paulo: Versal, 2014. 
MOXON, S. Sustentabilidade no design de Interiores. Amadora: Editorial Gustavo Gili, SL, 2012.

PAPANEK, V. Arquitectura e Design: ecologia e ética. Lisboa: Edição 70, 1995.

SARMENTO, A. C. de L.; SOUZA, P. F. de A. Indicadores de sustentabilidade aplicados ao design de interiores: análise do modelo IDSRS, p. 1885-1893 . In: Anais do 12 Congresso Brasileiro de Pesquisa e Desenvolvimento em Design [= Blucher Design Proceedings, v. 9, n. 2]. São Paulo: Blucher, 2016.

SARMENTO, A. C. de L. Sentir, perceber, notar e compreender a habitação: a experiência multissensorial no design de interiores - o exemplo de uma residência em Itacimirim - BA. $138 \mathrm{f}$. il. 2017. Dissertação (Mestrado) - Programa de Pós-Graduação em Artes Visuais, Universidade Federal da Bahia, 2017.

SOUZA, P. F. de A. Sustentabilidade e responsabilidade social no design do produto: rumo à definição de indicadores. 2007. 294 f. Tese de Doutorado - Faculdade de Arquitetura e Urbanismo, Universidade de São Paulo, São Paulo, 2007.

STEPHAN, A. P. A sustentabilidade e a contemporaneidade. In: JATOBÁ, Waldick (Org). In: Desafios do design sustentável brasileiro $=$ Challenges of Brazilian sustainable design. São Paulo: Versal, 2014. 